\title{
Biodegradation of 4-nitroanisole by two Rhodococcus spp.
}

\author{
Anke Schäfer, Hauke Harms \& Alexander J. B. Zehnder \\ Swiss Federal Institute for Environmental Science and Technology (EAWAG), and Swiss Federal Institute of \\ Technology (ETH), Überlandstrasse 133, CH-8600 Dübendorf, Switzerland
}

Accepted 27 February 1996

Key words: biodegradation, $O$-demethylation, metabolism, 4-nitroanisole, 4-nitrophenol

\begin{abstract}
Two Rhodococcus strains, R. opacus strain AS2 and R. erythropolis strain AS3, that were able to use 4-nitroanisole as the sole source of carbon and energy, were isolated from environmental samples. The first step of the degradation involved the $O$-demethylation of 4-nitroanisole to 4-nitrophenol which accumulated transiently in the medium during growth. Oxygen uptake experiments indicated the transformation of 4-nitrophenol to 4-nitrocatechol and 1,2,4-trihydroxybenzene prior to ring cleavage and then subsequent mineralization. The nitro group was removed as nitrite, which accumulated in the medium in stoichiometric amounts. In $R$. opacus strain AS2 small amounts of hydroquinone were produced by a side reaction, but were not further degraded.
\end{abstract}

\section{Introduction}

Nitroaromatic compounds have entered nature in large amounts as a result of their extensive use in the production of dyes, plastics, and explosives and their application as insecticides and herbicides. Since these chemicals are toxic and mutagenic, it is important to understand their fate once they enter the environment.

Although the nitro group renders the aromatic ring more resistant to biodegradation (Alexander 1994), several nitroaromatic compounds have been shown to be degraded by microorganisms (Higson 1992; Marvin-Sikkema \& de Bont 1994; Spain 1995). There are five ways of attacking the nitro group of nitroaromatic compounds. First, the nitro group can be removed as nitrite by a monooxygenase as has been described for a number of nitrophenols (Spain et al. 1979; Zeyer \& Kocher 1988). Second, the nitro group can be eliminated as nitrite, following a dioxygenasecatalyzed insertion of two hydroxyl groups (Spanggord et al. 1991; Haigler et al. 1994). Third, the nitro group can be reduced to an amino group, giving rise to aromatic amines which can or cannot be further degraded (Zeyer \& Kearney 1984; Preuss et al. 1993). Fourth, the nitro group can be eliminated reductively as nitrite (Lenke et al. 1992; Duque et al. 1993). Fifth, it can be partially reduced to hydroxylamines followed by a replacement reaction (Groenewegen et al. 1992; Haigler \& Spain 1993; Rhys-Williams et al. 1993) or Bamberger-like rearrangement reaction (Nishino \& Spain 1993) yielding catechols or phenols, respectively.

Nitroanisoles are of great importance in the chemical industry and have caused one of the biggest and most important accidents in the history of the German chemical industry (Heudorf \& Peters 1993). Nitroanisoles have been shown to disappear in bacterial mixed cultures (Wellens 1990) and to be transformed unspecifically to the corresponding highly toxic nitrophenols (Edelson \& McMullen 1977), but no complete mineralization has been reported yet. In this paper we describe the isolation of two Rhodococcus spp. strains that are able to use 4-nitroanisole as the sole source of carbon and energy. Additionally, we propose a pathway for the degradation of 4-nitroanisole by these two microorganisms. 


\section{Materials and methods}

Chemicals

4-Nitroanisole and 1,2,4-trihydroxybenzene were obtained from Aldrich Chemical Co. (Buchs, Switzerland). 4-Nitrophenol, 4-nitrocatechol, catechol, hydroquinone, and 2-nitroanisole were from Fluka (Buchs, Switzerland). 3-Nitroanisole and 3-nitrophenol were purchased from Merck (Dietikon, Switzerland), and 2-nitrophenol from Riedel-deHaen (Berlin, Germany).

\section{Isolation and identification of bacteria}

A mixture of soil samples of different origins was used to inoculate a mineral salts medium (Harms \& Zehnder 1994) supplemented with 4-nitroanisole (250 $\mathrm{mg} \mathrm{l}^{-1}$ ) as the sole source of carbon and energy. Batch enrichment cultures were incubated at $25^{\circ} \mathrm{C}$ on a rotary shaker. After several transfers of the enrichment culture $(10 \%$; vol/vol), samples of the culture were plated on solid medium, which was prepared by adding $1.5 \%$ agar to the mineral salts medium. A few crystals of 4-nitroanisole were distributed evenly on the agar plates. Two pure cultures that were able to grow on 4-nitroanisole as single carbon source could be isolated and were named AS2 and AS3. The 16S rRNA of both isolates was partially sequenced by the Deutsche Sammlung von Mikroorganismen und Zellkulturen (DSM, Braunschweig, Germany).

\section{Growth of bacteria}

$R$. opacus strain AS2 and $R$. erythropolis strain AS3 were cultivated in the mineral salts medium with 100 $\mathrm{mg} \mathrm{l}^{-1}$ or $50 \mathrm{mg} \mathrm{l}^{-1} 4$-nitroanisole, respectively. The concentration of 4-nitroanisole was specifically lower for $R$. erythropolis strain AS3 than for $R$. opacus strain AS2 because concentrations of $100 \mathrm{mg}^{-1}$ of nitroanisole were found to be toxic for the AS3 strain. Cultures were inoculated with $2 \%$ (vol/vol) nutrient broth-grown precultures and incubated at $30^{\circ} \mathrm{C}$ on a rotary shaker at $180 \mathrm{rpm}$. During the growth experiments, the optical density at $546 \mathrm{~nm}$ was followed photometrically. Samples were taken once every hour, centrifuged $\left(3 \mathrm{~min}\right.$ at $14,000 \times \mathrm{g}$ and $20^{\circ} \mathrm{C}$ ) and the supernatant stored at $-20^{\circ} \mathrm{C}$ until HPLC analysis and nitrite determination were performed.

For the respirometric assays, cells were grown overnight in the mineral medium containing one of the following C-sources: 4-nitroanisole ( $R$. opacus strain
AS2: $100 \mathrm{mg}^{-1} ; R$. erythropolis strain AS3: $50 \mathrm{mg}$ $1^{-1}$ ), 4-nitrophenol (addition of $7 \mathrm{mg} \mathrm{l}^{-1}$ every six to fourteen hours), ethanol $\left(2.88 \mathrm{ml} \mathrm{l}^{-1}\right)$, or glucose $\left(2 \mathrm{~g} \mathrm{l}^{-1}\right)$. For 4-nitroanisole and 4- nitrophenol as Csources, the medium was supplemented with $100 \mathrm{mg}$ $1^{-1}$ yeast extract. Bacteria were harvested by centrifugation at $4^{\circ} \mathrm{C}$ and $8,500 \times \mathrm{g}$. The cells were washed with $100 \mathrm{mM}$ pH 7.2 phosphate buffered saline (PBS) that contained $84.4 \mathrm{mM}$ of $\mathrm{NaCl}, 2.1 \mathrm{mM}$ of $\mathrm{KH}_{2} \mathrm{PO}_{4}$ and $6.8 \mathrm{mM}$ of $\mathrm{K}_{2} \mathrm{HPO}_{4}$. The bacteria were resuspended in a small volume of PBS and stored on ice until the measurements were performed.

\section{Substrate utilization}

Utilization of aromatic substrates was tested on solid media. Cells were inoculated on mineral salts medium agar in petri dishes. Some substrate crystals were distributed on the agar plates and the plates were incubated at $25^{\circ} \mathrm{C}$ for up to two weeks. We followed bacterial growth qualitatively and, in case of the colored substrates 4-nitrophenol and 4-nitrocatechol, observed the decolorization of the solid media.

\section{Metabolite production and isolation}

$R$. opacus strain AS2 and $R$. erythropolis strain AS3 were grown in $300 \mathrm{ml}$ of medium in $500 \mathrm{ml}$-bottles at room temperature. Aeration was achieved by stirring vigorously with magnetic stir bars. 4-Nitroanisole was added as the sole carbon source ( $R$. opacus strain AS2: $100 \mathrm{mg} \mathrm{l}^{-1} ; R$. erythropolis strain AS3: $50 \mathrm{mg}$ $1^{-1}$ ). Disappearance of 4-nitroanisole and formation of metabolites were followed by HPLC analysis. When all substrate was consumed and a considerable amount of metabolite had been formed, cells were removed by centrifugation, and the supernatants were extracted twice with half the volume of ethyl acetate. After drying the extract with anhydrous sodium sulfate and filtering it through a glass filter, the solvent was evaporated and the residue was dissolved in a small volume of methanol.

\section{Analytical methods}

HPLC analysis of the culture fluids was performed on a LiChrospher ${ }^{\circledR} 100$ RP- 8 column $(5 \mu \mathrm{m}), 215 \mathrm{~mm}$ by 4 $\mathrm{mm}$ internal diameter (Merck, Dietikon, Switzerland). The mobile phase was methanol-water $(60: 40 ; \mathrm{vol} / \mathrm{vol})$ with $0.05 \%$ phosphoric acid. The flow rate was set to 
$1 \mathrm{ml} \mathrm{min}-1$. 4-Nitroanisole and 4-nitrophenol were detected and quantified by their absorbance at 317 $\mathrm{nm}$ with a diode array detector 440 (Kontron Instruments, Schlieren, Switzerland). 4-Nitroanisole and 4nitrophenol exhibit UV-adsorption maxima at $316 \mathrm{~nm}$ (Haderlein \& Schwarzenbach 1993; Schwarzenbach et al. 1988). Both compounds were identified by comparison of retention times and UV spectra with those of authentic standards.

Mass spectra were obtained with a Finnigan MAT ITD 800 (ion trap detection) mass spectrometer (Finnigan MAT, San Jose, Calif.) coupled to a Carlo Erba HRGC 5160 Mega Series gas chromatograph (Carlo Erba Instruments, Milan, Italy) equipped with a $15 \mathrm{~m}$ PS086 (88\% Dimethyl, 12\% Diphenyl) glass capillary column. Electron ionization was used. The injection $(0.7 \mu \mathrm{l})$ was administered on column at $70^{\circ} \mathrm{C}$. The temperature program was run from 70 to $230^{\circ} \mathrm{C}$ with a rate of $10^{\circ} \mathrm{C} \mathrm{min}^{-1}$. Samples were dissolved in ethyl acetate and injected without derivatization.

Nitrite was determined colorimetrically according to the method of Moir et al. (1993). Oxygen uptake rates were determined with a Clark-type oxygen electrode at $30^{\circ} \mathrm{C}$. Reaction mixtures contained cells $\left(\mathrm{OD}_{546}=0.7-1.0\right)$ in $3 \mathrm{ml}$ of $100 \mathrm{mM}$ PBS. After recording the endogenous oxygen uptake, 50 $\mu \mathrm{M}$ of the aromatic substrate were added and the oxygen uptake was measured for another ten to twenty minutes. Oxygen uptake rates were calculated by subtracting the endogenous oxygen consumption. Protein contents of the reaction mixture were determined with the Bio-Rad Protein Microassay (Bio-Rad, Glattbrugg, Switzerland) after the cells had been broken by a cell homogenizer (Braun, Melsungen, Germany).

\section{Results}

\section{Characterization of the bacterial strains}

Identification of the strains was based on the following characteristics:

- both strains are gram-positive,

- they possess a pronounced cell cycle, and

- both strains contain $m$-diaminopimelic acid as diamino acid in the cell wall (data not shown).

We tentatively identified the strains as Rhodococcus spp. Partial 16S rRNA sequencing revealed $100 \%$ sequence homology with Rhodococcus opacus for strain AS2 and $99.5 \%$ sequence homology with Rhodococcus erythropolis for strain AS3. Because the

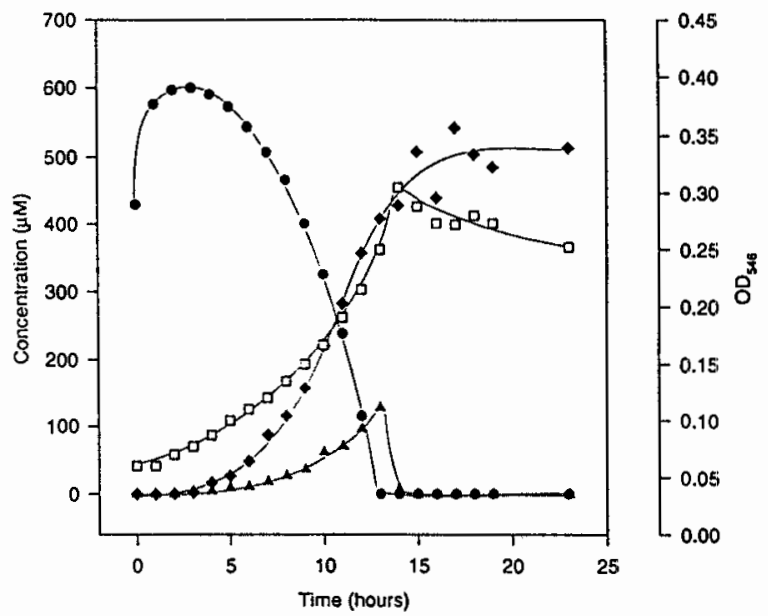

Figure I. Growth of R. opacus strain AS2 on 4-nitroanisole. Symbols represent 4-nitroanisole $(\Theta)$, 4-nitrophenol $(\boldsymbol{\Lambda})$, nitrite $(\boldsymbol{})$, and the $\mathrm{OD}_{546}(\square)$.

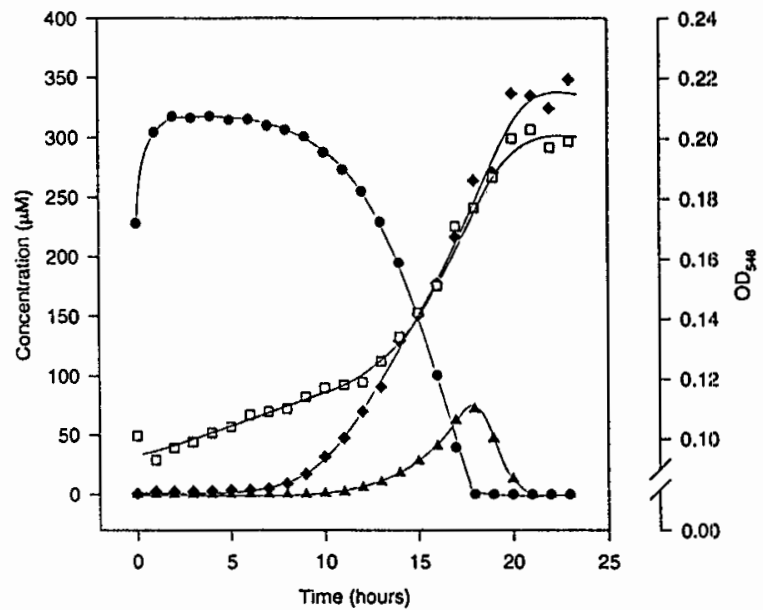

Figure 2. Growth of $R$. erythropolis strain AS3 on 4-nitroanisole. Symbols represent 4-nitroanisole ( $)$, 4-nitrophenol $(\boldsymbol{A})$, nitrite $(\widehat{)})$, and the $\mathrm{OD}_{546}(\square)$.

species level is reached at $99 \%$ 16S rRNA sequence homology, both strains can be designated to the respective species.

Growth of R. opacus strain AS2 and R. erythropolis strain AS3 on 4-nitroanisole

The growth of $R$. erythropolis strain AS2 and $R$. opacus strain AS3 with 4-nitroanisole as the only source of carbon and energy is shown in Figures 1 and 2. The con- 
centration of 4-nitroanisole increased during the first 3 hours because it had not yet dissolved completely at the beginning of the experiment. The amount of substrate added corresponded to $653 \mu \mathrm{M}$ for $R$. opacus strain AS2 and $326 \mu \mathrm{M}$ for $R$. erythropolis strain AS3. After five to ten hours the substrate concentration began to decrease rapidly. Complete degradation was achieved after 13 and 18 hours for AS2 and AS3, respectively. 4-Nitrophenol (for identification see below) transiently accumulated in the medium during growth of both strains, but disappeared soon after the complete degradation of 4-nitroanisole. 4-Nitrophenol never appeared in high concentrations indicating its subsequent metabolization during the degradation of 4-nitroanisole. The fact that 4-nitrophenol was only released transiently in minor amounts is further confirmed by the growth of cells which paralleled the decrease of nitroanisole. A small peak whose retention time corresponded to that of 4-nitrocatechol appeared transiently in both growth experiments (data not shown). The $\mathrm{OD}_{546}$ increased until all 4-nitroanisole had disappeared. The subsequent decrease in $\mathrm{OD}_{546}$ might be explained by the lysis of a fraction of the cells or by changes of the cell shape as a result of the cell cycle. The nitro group of 4nitroanisole was released into the medium as nitrite in stoichiometric amounts by $R$. erythropolis strain AS3, while only $80 \%$ of the expected nitrite was detected for $R$. opacus strain AS2. This deficiency can be explained by the fact that both strains are able to use nitrite as nitrogen source (data not shown). The doubling times of $R$. opacus strain AS2 and R. erythropolis strain AS3 were $5.9 \mathrm{~h}$ and $10.4 \mathrm{~h}$, respectively. Maximal specific degradation rates of 4-nitroanisole were $18.4 \mu \mathrm{mol} \mathrm{mg}$ protein ${ }^{-1} \mathrm{~h}^{-1}$ for R. opacus strain AS2 and $12.1 \mu \mathrm{mol}$ mg protein ${ }^{-1} \mathrm{~h}^{-1}$ for $R$. erythropolis strain AS3.

\section{Utilization of nitroaromatic substrates}

$R$. opacus strain AS2 grew on solid media with 4nitroanisole, 4-nitrophenol, 4-nitrocatechol, and catechol as the sole sources of carbon and energy, but not with hydroquinone, 2-nitroanisole, 3-nitroanisole, 2nitrophenol, or 3-nitrophenol. $R$. erythropolis strain AS3 showed the same substrate spectrum. Growth on 1,2,4-trihydroxybenzene could not be investigated with the method applied here since the compound spontaneously transforms to the red hydroxy1,4-benzoquinone in aqueous media (Jain et al. 1994). Degradation of in aqueous solution colored substrates 4-nitrophenol and 4-nitrocatechol by both strains could be seen from the decolorization of the plates. Growth free zones around the crystals of 4-nitroanisole and catechol indicated inhibition of growth by high concentrations of these compounds.

\section{Identification of metabolites}

The ethylacetate extracts of the supernatants of $R . o p a-$ cus strain AS2 and $R$. erythropolis strain AS3 both contained mainly one compound with an HPLC retention time and a UV-Vis spectrum identical to those of 4-nitrophenol (data not shown). In aqueous solution the metabolite exhibited a bright yellow color and an absorption maximum at $400 \mathrm{~nm}$ corresponding to the properties of 4-nitrophenolate. The mass-spectra (not shown) were identical to those of authentic 4nitrophenol. A small amount of hydroquinone could be detected by GCMS analysis in the ethylacetate extract of $R$. opacus strain AS2. In addition, ethylacetate extracts of both strains contained small quantities of a compound with the same retention time and UV-Vis spectrum as 4-nitrocatechol.

\section{Oxidation of aromatic compounds by resting cells}

The substrate specific oxygen consumption rates for a variety of substrates were measured in 4-nitroanisole-, 4-nitrophenol-, ethanol-, and glucose-grown cells (Table 1). Absolute oxygen consumption rates differed from experiment to experiment, though the normalized consumption rates were rather similar. This may be due to the fact that depending on the age of the preculture, the bacterial cultures grew with slightly different rates, and therefore, were harvested in slightly different physiological states. In Table 1 typical results for oxygen uptake rates are shown.

Oxygen consumption of 4-nitroanisole-grown cells of both strains was stimulated by 4nitroanisole, 4-nitrophenol, 4-nitrocatechol, and 1,2,4trihydroxybenzene. Catechol and 3-nitroanisole also stimulated the oxygen consumption significantly, although the rates were lower. 2-Nitrophenol was only oxidized by $R$. opacus strain AS2, and hydroquinone, 2-nitroanisole, and 3-nitrophenol were not oxidized at all. 4-Nitrophenol-grown cells generally showed lower oxygen consumption rates than 4 nitroanisole-grown cells which may reflect the high toxicity of nitrophenol. Normalized oxygen consumption rates of 1,2,4-trihydroxybenzene were higher for 4-nitrophenol-grown cells than for 4 -nitroanisolegrown cells. None of the nitroaromatic compounds were oxidized by cells grown on glucose or ethanol. 
Table 1. Specific oxygen uptake rates by resting cells of $R$. opacus strain AS2 and $R$. erythropolis strain AS3.

\begin{tabular}{|c|c|c|c|c|c|c|}
\hline \multirow[t]{2}{*}{ Strain and substrate } & \multicolumn{6}{|c|}{ Specific oxygen rates $\left(\mathrm{nmol} \mathrm{O} \min ^{-1} \mathrm{mg}\right.$ protein $\left.{ }^{-1}\right)$ after growth with } \\
\hline & \multicolumn{2}{|c|}{ 4-Nitroanisole } & \multicolumn{2}{|c|}{ 4-Nitrophenol } & \multirow[t]{2}{*}{ Glucose } & \multirow[t]{2}{*}{ Ethanol } \\
\hline & & & & & & \\
\hline 4-Nitroanisole & 568 & $(100 \%)$ & 192 & $(100 \%)$ & $<5$ & $\mathrm{ND}^{\mathrm{a}}$ \\
\hline 4-Nitrophenol & 249 & $(44 \%)$ & 91 & $(48 \%)$ & $<5$ & ND \\
\hline Hydroquinone & $<5$ & & $<5$ & & $<5$ & ND \\
\hline 1,2,4-Trihydroxybenzene & 86 & $(15 \%)$ & 70 & $(36 \%)$ & 18 & ND \\
\hline 4Nitrocatechol & 159 & $(28 \%)$ & 74 & $(38 \%)$ & $<5$ & ND \\
\hline Catechol & 12 & $(2 \%)$ & 8 & $(4 \%)$ & $<5$ & ND \\
\hline 2-Nitroanisole & $<5$ & & $<5$ & & $<5$ & ND \\
\hline 3-Nitroanisole & 10 & $(2 \%)$ & $<5$ & & $<5$ & ND \\
\hline 2-Nitrophenol & 24 & $(6 \%)$ & $<5$ & & $<5$ & ND \\
\hline 3-Nitrophenol & $<5$ & & $<5$ & & $<5$ & ND \\
\hline \multicolumn{7}{|l|}{ AS3 } \\
\hline 4-Nitroanisole & 390 & $(100 \%)$ & 101 & $(100 \%)$ & ND & $<5$ \\
\hline 4Nitrophenol & 154 & $(39 \%)$ & 18 & $(18 \%)$ & ND & $<5$ \\
\hline Hydroquinone & $<5$ & & $<5$ & & ND & $<5$ \\
\hline 1,2,4-Trihydroxybenzene & 111 & $(28 \%)$ & 102 & $(101 \%)$ & ND & 5 \\
\hline 4Nitrocatechol & 66 & $(17 \%)$ & 18 & $(18 \%)$ & ND & $<5$ \\
\hline Catechol & 27 & $(7 \%)$ & $<5$ & & ND & $<5$ \\
\hline 2-Nitroanisole & $<5$ & & $<5$ & & ND & $<5$ \\
\hline 3-Nitroanisole & 20 & $(4 \%)$ & $<5$ & & ND & $<5$ \\
\hline 2-Nitrophenol & $<5$ & & $<5$ & & $\mathrm{ND}$ & $<5$ \\
\hline 3-Nitrophenol & $<5$ & & $<5$ & & ND & $<5$ \\
\hline
\end{tabular}

${ }^{\mathrm{a}} \mathrm{ND}=$ Not Determined.

\section{Discussion}

We have been able to isolate two Rhodococcus strains that are capable of using 4-nitroanisole as the sole source of carbon and energy. A metabolite that accumulated transiently in the medium during growth of both strains was identified as 4-nitrophenol by GCMS. This suggests an $O$-demethylation of 4-nitroanisole to 4-nitrophenol. Escherichia coli has been reported to $O$ demethylate 4-nitroanisole to 4-nitrophenol (Edelson \& McMullen 1977), but was not able to metabolize 4nitrophenol any further. $O$-Demethylation of methoxylated aromatic compounds to the corresponding phenols has been described for a number of compounds under aerobic (Bernhardt et al. 1977; Cartwright \& Smith 1967) and anaerobic conditions (Bache \& Pfennig 1981; Frazer \& Young 1986). According to existing reports, the aerobic removal of the methyl group is conducted by a monooxygenase. Iron-sulfur proteins (Bernhardt et al. 1975) and cytochromes P--450 (Sutherland 1986; Karlson et al. 1993) have been shown to be responsible for this reaction. Cartwright \& Smith (1967) reported that the methyl group is removed as formaldehyde and converted via formate to carbon dioxide under aerobic conditions.

For the degradation of 4-nitrophenol, two possible pathways have been described. One pathway involves the transformation of 4-nitrophenol to hydroquinone via 4-benzoquinone and then subsequent conversion to $\gamma$-hydroxymuconic semialdehyde and maleylacetate (Spain et al. 1979; Spain \& Gibson 1991). Alternatively, 4-nitrophenol can be converted to maleylacetate via 4-nitrocatechol and 1,2,4trihydroxybenzene (Jain et al. 1994). Oxygen uptake of whole cells of $R$. opacus strain AS2 and R. erythropolis strain AS3 could be increased by 4-nitrocatechol or 1,2,4-trihydroxybenzene, but not by hydroquinone (Tab.1). The nitrophenol-degrading strains both exhibited increased oxygen uptake rates for 4-nitrocatechol and 1,2,4-trihydroxybenzene as the substrates (Spain et al. 1979; Spain \& Gibson 1991). However, in case of degradation of 4-nitrophenol via hydroquinone, large oxygen uptake rates with hydroquinone as the substrate were reported (Spain \& Gibson 1991), whereas for degradation of 4-nitrophenol via 4-nitrocatechol, no oxygen uptake with hydroquinone was detected (Jain 
<smiles>COc1ccc([N+](=O)[O-])cc1</smiles><smiles>C1CCCCC1</smiles><smiles>O=[N+]([O-])c1ccc(O)cc1</smiles>

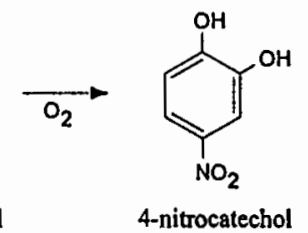

4-nitroanisole

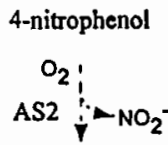

4-nitrocatechol

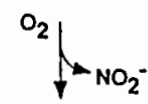<smiles>Oc1ccc(O)cc1</smiles>

hydroquinone

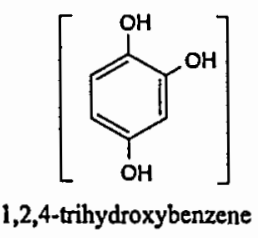

TCA-cycle

Figure 3. Proposed pathway for the degradation of 4-nitroanisole by $R$. opacus strain AS2 and R. erythropolis strain AS3.

et al. 1994). For our isolates, $R$. opacus strain AS2 and $R$. erythropolis strain AS3, the absence of any activity towards hydroquinone strongly indicates the degradation of 4-nitrophenol via 4-nitrocatechol and 1,2,4-trihydroxybenzene as depicted in Figure 3 . This assumption is supported by the fact that traces of 4nitrocatechol could be detected in ethylacetate extracts of both strains.

4-Nitroanisole is demethylated by an oxygenase to 4-nitrophenol. The methyl group is probably removed as formaldehyde, that may be further oxidized to carbon dioxide (Cartwright \& Smith 1967). 4-Nitrophenol is hydroxylated to 4-nitrocatechol. Subsequently, the nitro group is removed by an oxygenase and released as nitrite. The stoichiometric release of nitrite confirms this nitro group elimination. The resulting 1,2,4trihydroxybenzene can be cleaved and fed into the tricarboxylic acid cycle. A minor metabolic side reaction led to the formation of small amounts of hydroquinone by $R$. opacus strain AS2. Because R. opacus strain AS2 is unable to grow on hydroquinone on solid medium, or to degrade hydroquinone in liquid medium (data not shown), and its oxygen uptake rate is not stimulated by hydroquinone, it was assumed that the hydroquinone detected is a dead end product.

We have shown that the degradation of 4nitroanisole by two Rhodococcus spp. involves the

transient accumulation of 4-nitrophenol in the medium. 4-Nitrophenol is much more toxic than 4-nitroanisole because it can uncouple the proton transport in the membrane and thereby inhibit ATP-production. As a consequence, when the prediction of the fate of nitroanisoles in the environment is intended, one has to take into account that bacteria can not only metabolize chemicals in a beneficial way, but can also generate even more hazardous compounds. These compounds may accumulate under certain conditions and prevent further degradation.

\section{Acknowledgment}

This research has been conducted as part of the OPUSIA project and has been supported by the Board of the Swiss Federal Institutes of Technology.

\section{References}

Alexander M (1994) Effect of chemical structure on biodegradation. In: Biodegradation and Bioremediation (pp 159-176). Academic Press, San Diego

Bache R \& Pfennig N (1981) Selective isolation of Acetobacterium woodii on methox ylated aromatic acids and determination of growth yields. Arch. Microbiol. 130: 255-261

Bernhardt FH, Nastainczyk W \& Seydewitz V (1977) Kinetic studies on a 4-methoxybenzoate $O$-demethylase from $P$ seudomonas putida. Eur. J. Biochem. 72: 107-115

Bernhardt FH, Pachowsky H \& Staudinger H (1975) A 4methoxybenzoate $O$-demethylase from Pseudomonas putida: a new type of monooxygenase system. Eur. J. Biochem. 57: 241256

Cartwright NJ \& Smith ARW (1967) Bacterial attack on phenolic ethers: an enzyme system demethylating vanillic acid. Biochem. J. 102: 826-841

Duque E, Haidour A, Godoy F \& Ramos JL (1993) Construction of a Pseudomonas hybrid strain that mineralizes 2,4,6-trinitrotoluene. J. Bacteriol. 175: 2278-2283

Edelson J \& McMullen JP (1977) O-Demethylation of $p$-nitroanisole by Escherichia coli. Stimulation by phenobarbital. Drug Metab. Dispos. 5: 185-190

Frazer AC \& Young LY (1986) Anaerobic $C_{1}$ metabolism of the $O$-methyl- ${ }^{14} \mathrm{C}$-labeled substituent of vanillate. Appl. Environ. Microbiol. 51: 84-87

Groenewegen PEJ, Breeuwer P, van Helvoort JMLM, Langenhoff AAM, de Vries FP \& de Bont JAM (1992) Novel degradative pathway of 4-nitrobenzoate in Comamonas acidovorans NBA10. J. Gen. Microbiol. 138: 1599-1605

Haderlein SB \& Schwarzenbach RP(1993) Adsorption of substituted nitrobenzenes and nitrophenols to mineral surfaces. Environ. Sci. Technol. 27: 316-326

Haigler BE \& Spain JC (1993) Biodegradation of 4-nitrotoluene by Pseudomonas sp. strain 4NT. Appl. Environ. Microbiol. 57: 3156-3162 
Haigler BE, Wallace WH \& Spain JC (1994) Biodegradation of 2-nitrotoluene by Pseudomonas sp. strain JS42. Appl. Environ. Microbiol. 60: 3466-3469

Harms H \& Zehnder AJB (1994) Influence of substrate diffusion on degradation of dibenzofuran and 3-chlorodibenzofuran by attached and suspended bacteria. Appl. Environ. Microbiol. 60: 2736-2745

Heudorf U \& Peters M (1993) Umweltbelastung und Sanierungsverlauf nach dem Störfall in der Fa. Hoechst AG vom 22. 2. 1993. Forum Städte-Hygiene 44: 338-344

Higson FK (1992) Microbial degradation of nitroaromatic compounds. Adv. Appl. Microbiol. 37: 1-19

Jain RK, Dreisbach JH \& Spain JC (1994) Biodegradation of pnitrophenol via 1,2,4-benzenetriol by an Arthrobacter species. Appl. Environ. Microbiol. 60: 3030-3032

Karlson U, Dwyer DF, Hooper SW, Moore ERB, Timmis KN \& Eltis LD (1993) Two independently regulated cytochromes $P-450$ in a Rhodococcus rhodochrous strain that degrades 2-ethoxyphenol and 4-methoxybenzoate. J. Bacteriol. 175: 1467-I474

Lenke H, Pieper DR, Bruhn C \& Knackmuss H-J (1992) Degradation of 2,4-dinitrophenol by two Rhodococcus erythropolis strains, $\mathrm{HL}$ 24-1 and HL 24-2. Appl. Environ. Microbiol. 58: 2928-2932

Marvin-Sikkema FD \& de Bont JAM (1994) Degradation of nitroaromatic compounds by microorganisms. Appl. Microbiol. Biotechnol. 42: 499-507

Moir JWB, Baratta D, Richardson DJ \& Ferguson SJ (1993) The purification of a $c d_{1}$-type nitrite reductase from, and the absence of a copper-type nitrite reductase from, the aerobic denitrifier Thiosphaera pantotropha; the role of pseudoazurin as an electron donor. Eur. J. Biochem. 212: 377-385

Nishino SF \& Spain JC (1993) Degradation of nitrobenzene by a Pseudomonas pseudoalcaligenes. Appl. Environ. Microbiol. 59: 2520-2525
Preuss A, Fimpel J \& Diekert G (1993) Anaerobic transformation of 2,4,6-trinitrotoluene (TNT). Arch. Microbiol. 159: 345-353

Rhys-Williams W, Taylor SC \& Williams PA (1993) A novel pathway for the catabolism of 4-nitrotoluene by Pseudomonas. J. Gen. Microbiol. 139: 1967-1972

Schwarzenbach RP, Stierii R, Lanz K \& Zeyer J (1988) Compound properties relevant for assessing the environmental partitioning of nitrophenols. Environ. Sci. Technol. 22: 83-92

Spain JC, Wyss O \& Gibson DT (1979) Enzymatic oxidation of $p$-nitrophenol. Biochem. Biophys. Res. Commun. 88: 634-641

Spain JC \& Gibson DT (1991) Pathway for biodegradation of $p$ nitrophenol in a Moraxella sp. Appl. Environ. Microbiol. 57: 812-819

Spain JC (1995) Biodegradation of nitroaromatic compounds. Annu. Rev. Microbiol. 49: 523-555

Spanggord RJ, Spain JC, Nishino SF \& Mortelmans KE (1991) Biodegradation of 2,4-dinitrotoluene by a Pseudomonas sp. Appl. Environ. Microbiol. 57: 3200-3205

Sutherland JB (1986) Demethylation of veratrole by cytochrome $\mathrm{P}-450$ in Streptomyces setonii. Appl. Environ. Microbiol. 52: 98-100

Wellens H (1990) Zur biologischen Abbaubarkeit mono- und disubstituierter Benzolderivate. Z. Wasser-Abwasser-Forsch. 23: 8598

Zeyer J \& Kearney PC (1984) Degradation of $o$-nitrophenol and $m$ nitrophenol by a Pseudomonas putida. J. Agric. Food. Chem. 32: 238-242

Zeyer J \& Kocher HP (1988) Purification and characterization of a bacterial nitrophenol oxygenase which converts orthonitrophenol to catechol and nitrite. J. Bacteriol. 170: 1789-1794 